\title{
Flow Sorting of Microorganisms for Molecular Analysis
}

\author{
GÜNTER WALLNER,,${ }^{1} \dagger$ BERNHARD FUCHS, ${ }^{2}$ STEFAN SPRING,${ }^{3}$ WOLFGANG BEISKER,,${ }^{1}$ \\ AND RUDOLF AMANN ${ }^{2 *}$ \\ GSF-Forschungszentrum für Umwelt und Gesundheit, Durchflußzytometrie, D-85764 Neuherberg, ${ }^{1}$ Max-Planck-Institut \\ für Marine Mikrobiologie, D-28359 Bremen, ${ }^{2}$ and Technische Universität München, Lehrstuhl für \\ Mikrobiologie, D-80290 Munich, ${ }^{3}$ Germany
}

Received 7 July 1997/Accepted 4 September 1997

\begin{abstract}
Not only classical cultivation-based methods but also the new molecular approaches may result in incomplete and selective information on the natural diversity of microbial communities. Flow sorting of microorganisms from environmental samples allows the deliberate selection of cell populations of interest from highly diverse systems for molecular analysis. Several cellular parameters that can be measured by flow cytometry are useful as sort criteria. Here, we report sorting of bacteria from activated sludge, lake water, and lake sediment according to differences in light scattering, DNA content, and/or affiliation to certain phylogenetic groups as assessed by fluorescein-labeled, rRNA-targeted oligonucleotide probes. Microscopy of the sorted cells showed that populations of originally low abundance could be strongly enriched by flow sorting (up to 280-fold), depending on the original abundance of the cells of interest and the type of sample sorted. The purity of the cells of interest could be further increased by repeated sorting, but this increase was limited by cell aggregation in the case of activated-sludge samples. It was possible to amplify almost full-length 16S ribosomal DNA (rDNA) fragments from sorted microbial cells by PCR, even after fixation with paraformaldehyde and in situ hybridization. Dot blot hybridization and sequencing demonstrated that most of the amplified rDNA originated from those cells that had been selected for by flow sorting. Comparative analysis of 16S rDNA sequences revealed previously unknown species of magnetotactic or activated-sludge bacteria.
\end{abstract}

The advent of molecular techniques, most notably the rRNA approach to microbial ecology and evolution as defined by $\mathrm{N}$. Pace, D. A. Stahl, and coworkers (19), had a large impact on our perception of microbial diversity and on the methods to study it. Whereas the first century of scientific microbiology had almost solely, and indeed very successfully, relied on cultivation-based methods, the last decade has seen numerous cultivation-independent studies based on the direct retrieval of sequence information from the environment (for a review, see reference 4). Indications of a vast undiscovered diversity were found by the new methods. Their use promises a more full and accurate description of the true microbial diversity as well as the structure and dynamics of complex microbial communities. However, based on various observations in the past several years it is increasingly being realized that the new methods are subject to problems similar to those encountered in the period of classical microbe hunting. One is that rRNA gene fragments of less-abundant microorganisms tend to be underrepresented in PCR amplification $(14,18)$ very much like less-abundant colonies have been neglected on agar plates. It could be argued that these less-abundant populations are likely to be of minor importance for a given ecosystem, but one should realize that, e.g., in soil a $0.1 \%$ population is still equivalent to about $10^{6}$ to $10^{8}$ cells per gram. Even more disturbingly, however, it is possible, and several reports have already described such occurrences, that major populations could be missed due to unwanted selectivity in one or several of the steps involved in the molecular assessment of microbial diversity. This is similar to the selectivity problem of classical enrichment and isolation

\footnotetext{
* Corresponding author. Mailing address: Max-Planck-Institut für Marine Mikrobiologie, Celsiusstr. 1, D-28359 Bremen, Germany. Phone: 494212028 930. Fax: 494212028790.

$\dagger$ Present address: Hoechst Marion Roussel, Quality Operations Microbiology, D-65926 Frankfurt am Main, Germany.
}

techniques. Among the biases of the molecular approach are uneven DNA extraction from gram-positive and gram-negative bacteria (20), differences in the number of rRNA operons per cell (4), disproportional amplification during PCR (23, 24), and differences in cloning efficiency (23), to name just the more important ones.

In contrast, the selectivity introduced by flow cytometric sorting is intended and defined, and it may allow some of the problems described above to be circumvented. Flow cytometry (FCM) is a well-established technology in medical diagnostics. For the application described here, two properties are important: (i) speed, i.e., up to $10^{2}$ to $10^{3}$ cells can be analyzed per second, and (ii) a sorting option that can physically enrich defined populations (for an overview, see references 8, 22, and 28). Applications of FCM to microbiology are frequently hindered by the small size and the concomitant low signal intensities of microbial cells (37). However, sensitive flow cytometers today allow the classification of many microbial cells according to their cell size $(25,36)$, DNA content (6), and specific staining conferred by fluorescent antibodies $(26,41$, $47)$ or rRNA-targeted oligonucleotide probes $(2,15,29,45-$ 47). It was the goal of this study to sort selected cell types from water, sediment, and activated-sludge samples by various FCM criteria and to investigate whether the sorted cells are amenable for molecular analysis. If so, it should be possible to focus on less-abundant but conspicuous populations and, on the other hand, to remove from analyses those molecular weeds that interfere with the retrieval of sequences even of abundant populations.

\section{MATERIALS AND METHODS}

Cells and fixation. The following pure cultures were grown according to the respective strain catalogues: Acinetobacter baumannii LMG $1041^{\mathrm{T}}$ (Laboratorium voor Microbiologie [LMG], Universiteit Gent, Ghent, Belgium), Aeromonas hydrophila TUB 953 (Stammsammlung der Technischen Universität Berlin [TUB], Berlin, Germany), Aquaspirillum metamorphum DSM $1837^{\mathrm{T}}$ (Deutsche $^{-}$ Sammlung von Mikroorganismen und Zellkulturen [DSM], Braunschweig, Ger- 
many), Bacillus subtilis DSM 402, Brevundimonas diminuta DSM 1635, Cytophaga johnsonii LMG $1341^{\mathrm{T}}$, Enterobacter cloacae WS 1293 (Sammlung des Instituts für Mikrobiologie, Forschungszentrum für Milch- und Lebensmittel [WS], TU München, Freising-Weihenstephan, Germany), Escherichia coli ATCC $11775^{\mathrm{T}}$ (American Type Culture Collection [ATCC], Rockville, Md.), Haliscomenobacter hydrossis DSM $1100^{\mathrm{T}}$, Leptothrix cholodnii LMG 9467, Leptothrix discophora LMG $8141^{\mathrm{T}}$, Microbacterium imperiali DSM 20530, Micrococcus kristinae ATCC $27570^{\mathrm{T}}$, Nocardia calcarea DSM 43065, Paracoccus denitrificans DSM $65^{\mathrm{T}}$, Rhodococcus rhodochrous DSM 43241, Sphaerotilus natans LMG $7172^{\mathrm{T}}$, Sphingomonas yanoikuyae LMG $11252^{\mathrm{T}}$, and Thiothrix nivea DSM 5205. Magnetotactic bacteria were enriched from the sediment of a large freshwater lake (Chiemsee, Upper Bavaria, Germany) as previously described (34) and fixed by the addition of 2 volumes of methanol. The fixed cells were further purified by filtration with a gauze filter (mesh size, $37 \mu \mathrm{m}$ ) to remove large cell aggregates. After filtration the cells were centrifuged, and the pellet was resuspended in phosphate-buffered saline (130 mM sodium chloride, $10 \mathrm{mM}$ sodium phosphate [pH 8.4]). Freshwater samples also were collected from Lago di Cadagno, a meromiktic lake in Switzerland at an altitude of $1,923 \mathrm{~m}$, at the chemocline in a depth of $13 \mathrm{~m}$. Samples of activated sludge were taken from aeration stage I of the municipal wastewater treatment plant München I (Großlappen, 2 million population equivalents). Fixation of the water samples and activated sludge was done with $3 \%$ paraformaldehyde as described before (3).

Hybridization and DNA staining. The following oligonucleotide probes were used under standard conditions: EUB (5'-GCTGCCTCCCGTAGGAGT-3'; specific for bacteria [2]), ACA (5'-ATCCTCTCCCATACTCTA-3'; specific for Acinetobacter spp. [44]), LDI (5'-CTCTGCCGCACTCCAGCT-3'; specific for Leptothrix spp. and related bacteria [42]). For fluorescent in situ hybridization, probes were labeled with 5(6)-carboxyfluorescein- $N$-hydroxysuccinimide-ester (MWG-Biotech, Ebersberg, Germany). For dot blot hybridizations, oligonucleotides were linked to horseradish-peroxidase (HRP) (Interactiva, Ulm, Germany) as described before (40). For FCM analysis, cells were hybridized in a buffer containing $0.9 \mathrm{M}$ sodium chloride, $0.1 \%$ sodium dodecyl sulfate, $20 \mathrm{mM}$ Tris- $\mathrm{HCl}(\mathrm{pH} 7.2)$, and $2 \mathrm{ng}$ of oligonucleotide $\mu \mathrm{l}^{-1}$ at $46^{\circ} \mathrm{C}(45,46)$. After $3 \mathrm{~h}$ of incubation, cells were centrifuged, washed in hybridization buffer for $0.5 \mathrm{~h}$, and resuspended in phosphate-buffered saline containing $1 \mu \mathrm{M}$ DAPI $\left(4^{\prime}, 6-\right.$ diamidino-2-phenylindole; Sigma, Deisenhofen, Germany). Cells immobilized on microscopic slides were hybridized and stained as described previously (43). Dot blot hybridizations were performed according to Manz et al. (17).

Flow cytometry and sorting. Flow cytometric analyses and cell sorting were performed with a FACStar Plus (Becton Dickinson, Mountain View, Calif.) cell sorter equipped with two argon ion lasers. The 488-nm emission line of the first laser, with an output power of $500 \mathrm{~mW}$, was used for measuring forward-angle light scatter (FSC; 488-nm band pass filter for detection) and right-angle light scatter (SSC; 488-nm band pass filter) as well as the fluorescence of the fluorescein-labeled probes (530-nm band pass filter). DAPI fluorescence was measured with a 424-nm band pass filter after excitation with the second laser tuned to UV (multilines 351.1 to $363.8 \mathrm{~nm}, 80 \mathrm{~mW}$ ). Data were collected in list mode as pulse height signals (four decades in logarithmic scale each). For cell sorting the "Normal-R" modus was chosen, which gives both high purity and recovery.

For sorting, the drop drive frequency was set at approximately $27 \mathrm{kHz}, 3$ drops were simultaneously deflected, and droplet delay was set between 12 and 15 . For sorting, $0.1 \%$ sodium chloride was used as sheath fluid. This relatively low salt concentration was chosen as a compromise between a reasonable charge and deflection of sort droplets on the one hand and the avoidance of salt crystals for microscopy or interference of salt with PCR on the other hand. Sort criteria were defined by drawing polygonal gates in bivariate histograms (dot plots of the two most informative flow cytometric parameters) with the Lysis II software package (Becton Dickinson). In order to check if the selected populations really included the desired type of cells, the gated cells were first sorted directly onto microscopic slides. After microscopic confirmation of the purity and correctness of cell sorting, sorted cells were collected in sterile 1.5 -ml reaction tubes for PCR.

PCR, cloning, and sequencing of 16S rDNA from sorted cells. Collected cells (usually 40 to $60 \mu \mathrm{l}$ ) were diluted with autoclaved distilled water to $1 \mathrm{ml}$ and pelleted by centrifugation $(5,000 \times g, 5 \mathrm{~min})$. The supernatant was discarded, and the cells were suspended in $70 \mu \mathrm{l}$ of autoclaved distilled water and freeze-thawed before being used directly for PCR amplification of almost full-length bacterial 16S rRNA gene fragments (modified from reference 34). The PCR mixture contained $10 \mu \mathrm{l}$ of $10 \times$ PCR buffer $(500 \mathrm{mM} \mathrm{KCl,} 100 \mathrm{mM}$ Tris-HCl [pH 9.0], $1 \%$ Triton X-100), $5 \mu \mathrm{l}$ of $25 \mathrm{mM} \mathrm{MgCl}, 2 \mu \mathrm{l}$ of $10 \mathrm{mM}$ (each) deoxynucleoside triphosphate, $25 \mathrm{pmol}$ of each primer, and the washed cells. The nucleotide sequences of the primers used for PCR were 5'-AGAGTTTGATYMTGGCTC AG-3' (Escherichia coli 16S rRNA positions 8 to 27 [5]) and 5'-CAKAAAGG AGGTGATCC-3' (E. coli 16S rRNA positions 1529 to 1546 [5]). The mixture was filled up to $100 \mu \mathrm{l}$ with double-distilled, sterile water in a $0.5-\mathrm{ml}$ reaction tube, overlaid with mineral oil (Sigma), and boiled for $5 \mathrm{~min}$ at $95^{\circ} \mathrm{C}$. Before starting the PCR cycling, $1.5 \mathrm{U}$ of Taq polymerase (Promega, Madison, Wis.) was added. After 35 cycles $\left(1 \mathrm{~min}\right.$ at $94^{\circ} \mathrm{C}, 2 \mathrm{~min}$ at $48^{\circ} \mathrm{C}, 3 \mathrm{~min}$ at $\left.72^{\circ} \mathrm{C}\right)$ the amplificate was analyzed by agarose gel electrophoresis $(1 \%$, wt $/ \mathrm{vol})$, purified with the Magic Prep kit (Serva, Heidelberg, Germany), and subsequently cloned into the pGEM-T-Vector (Promega, Heidelberg, Germany). Clones were detected by blue/white screening with IPTG (isopropyl- $\beta$-D-thiogalactopyranoside)
TABLE 1. Number of clones containing specific 16S rRNA sequences after PCR amplification and cloning of rDNA from enrichments of magnetotactic bacteria

\begin{tabular}{cccccc}
\hline \multirow{2}{*}{ Cell morphology } & \multicolumn{2}{c}{ Before cell sorting } & & \multicolumn{2}{c}{ After cell sorting } \\
\cline { 2 - 3 } \cline { 5 - 6 } & $\begin{array}{c}\text { Frequency }^{a} \\
(\%)\end{array}$ & $\begin{array}{c}\text { No. of } \\
\text { clones }^{b}\end{array}$ & $\begin{array}{c}\text { Frequency } \\
(\%)\end{array}$ & $\begin{array}{c}\text { No. of } \\
\text { clones }\end{array}$ \\
\hline $\begin{array}{c}\text { M. bavaricum, rod, ca. } \\
8 \mu \mathrm{m} \text {, magnetic }\end{array}$ & 50 & 1 & & $>95$ & 7 \\
$\begin{array}{c}\text { Curved rod, ca. } 8 \mu \mathrm{m}, \\
\text { magnetic }\end{array}$ & $<10$ & 0 & & $<5$ & 1 \\
$\begin{array}{c}\text { Unidentified bacterium, } \\
\text { nonmagnetic }\end{array}$ & $<5$ & 0 & & ND & 1 \\
$\begin{array}{c}\text { Cocci, ca. 2 } \mu \mathrm{m}, \\
\text { magnetic }\end{array}$ & 40 & 31 & & ND & 0 \\
$\begin{array}{c}\text { Contaminating bacteria } \\
\text { or DNA, } \\
\text { nonmagnetic }\end{array}$ & $\mathrm{ND}^{c}$ & 22 & & ND & 0 \\
\hline
\end{tabular}

${ }^{a}$ Percentage of the different morphotypes, estimated from microscopic examinations of the magnetic field enrichment.

${ }^{b}$ Origin determined by comparative sequence analysis and fluorescent in situ hybridization with rRNA-targeted probes derived from the new sequences. Cells were enriched by imposing a magnetic field or with additional flow sorting.

${ }^{c} \mathrm{ND}$, not detected.

and X-Gal (5-bromo-4-chloro-3-indolyl- $\beta$-D-galactoside). Plasmids were extracted by using the QIAprep-spin kit (Qiagen, Hilden, Germany).

Partial ( $>600$ bases) and full-length 16S rDNA sequences were determined on both strands with a LICOR automated sequencer (MWG-Biotech). Cycle sequencing protocols based upon the chain termination technique (7) were applied according to the manufacturer's instructions (Boehringer GmbH, Mannheim, Germany). Sequence analysis was performed with the ARB software package (38).

\section{RESULTS}

Sorting of magnetotactic bacteria based on cell size and internal structures. The first case in which we used flow cytometry to facilitate amplification and cloning of $16 \mathrm{~S}$ rDNA of a particular, morphologically conspicuous bacterium from a magnetic field enrichment of freshwater lake sediment was based on the specific light scattering of a large rod-shaped magnetotactic bacterium containing high numbers of magnetosomes (Magnetobacterium bavaricum [35]). Even though this cell type accounted for about $50 \%$ of all cells in an enrichment of magnetotactic bacteria from the Chiemsee sediment (Table 1 ) its $16 \mathrm{~S}$ rDNA initially could not be obtained. Later more detailed analysis demonstrated that only 1 of 54 clones tested from the original 16S rDNA library contained the rDNA fragment of interest. In situ hybridization assigned most of the cloned 16S rDNA sequences to the magnetotactic cocci that made up the second-most-abundant fraction in the enrichment (Table 1). Furthermore, numerous clones were presumably derived from contaminating free DNA or nonmagnetotactic cells that might still have been present in low numbers.

Accurate flow cytometric sorting was based on the strong forward- and side-scatter signals resulting from the large size and high content of magnetosomes of M. bavaricum (Fig. 1). Microscopy confirmed that the cells of interest had been further enriched to a purity of at least $95 \%$. Comparative analysis of nine randomly chosen clones of a second rDNA library made from the sorted cell fraction yielded seven identical sequences. By in situ hybridization this sequence could indeed be assigned to $M$. bavaricum. Of the two remaining sequences one could be assigned to another large, slightly curved magnetotactic rod-shaped bacterium, whereas the other probably originated from a large but nonmagnetic bacterium (Table 1). 


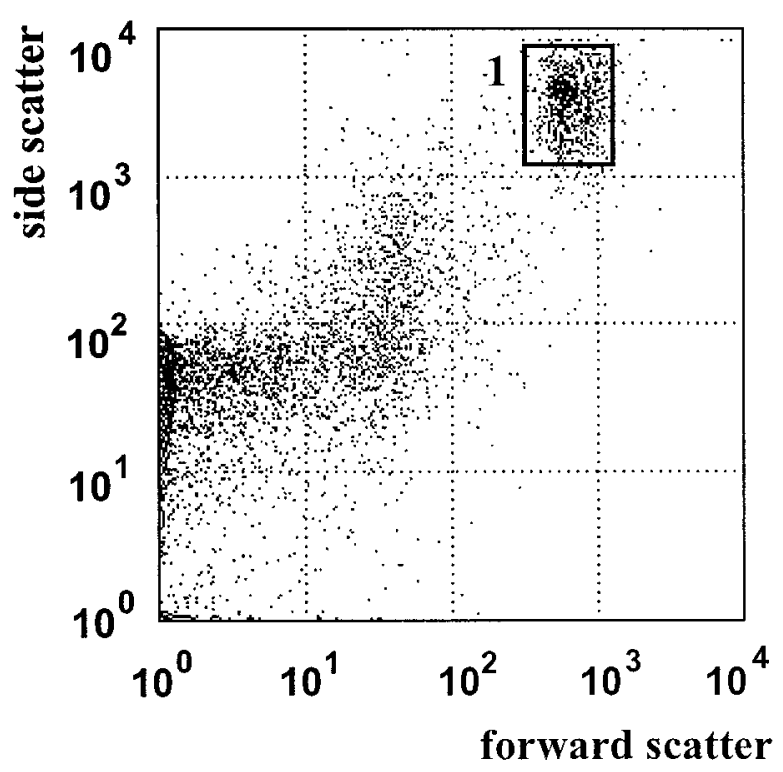

FIG. 1. Dot plot showing the gate (1) for sorting large cells from the enrichment of magnetotactic bacteria. Each dot represents a cell.

Sorting of bacteria from lake water based on cell morphology and DAPI staining. In freshwater samples collected at the chemocline from Lago di Cadagno, large curved rods were strikingly evident in microscopic examinations. These cells were present in relatively low abundance in the original sample $(<5 \%$ ) (39), but due to their large size (about 5 by $1 \mu \mathrm{m})$ they made up a large fraction of the biomass of planktonic bacteria and could therefore be of ecological importance. Prior to flow sorting, water samples were stained with DAPI. In bivariate plots of DAPI fluorescence versus forward scatter two populations were separated (Fig. 2). By subsequent sorting of these populations two distinct types of cells were obtained. Gate 1

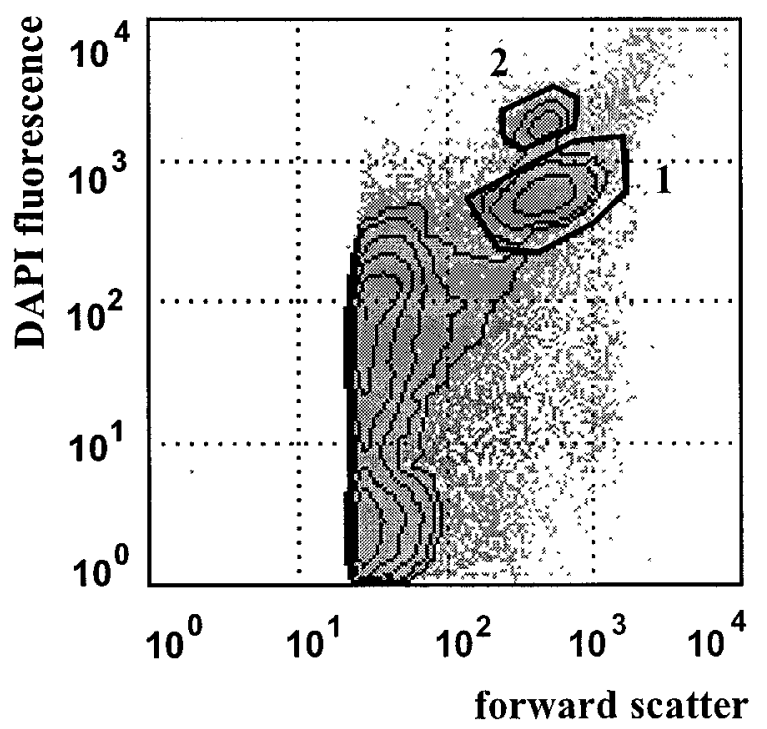

FIG. 2. Sorting of DAPI-stained bacteria from the chemocline of Lago di Cadagno. Frequencies can be estimated from the density of the dots and the overlaid contour lines $(3,6,12,24,48$, and $95 \%$ of maximum frequencies; outer to inner lines). Gate 2 encompassed the large curved rods shown in Fig. 3.

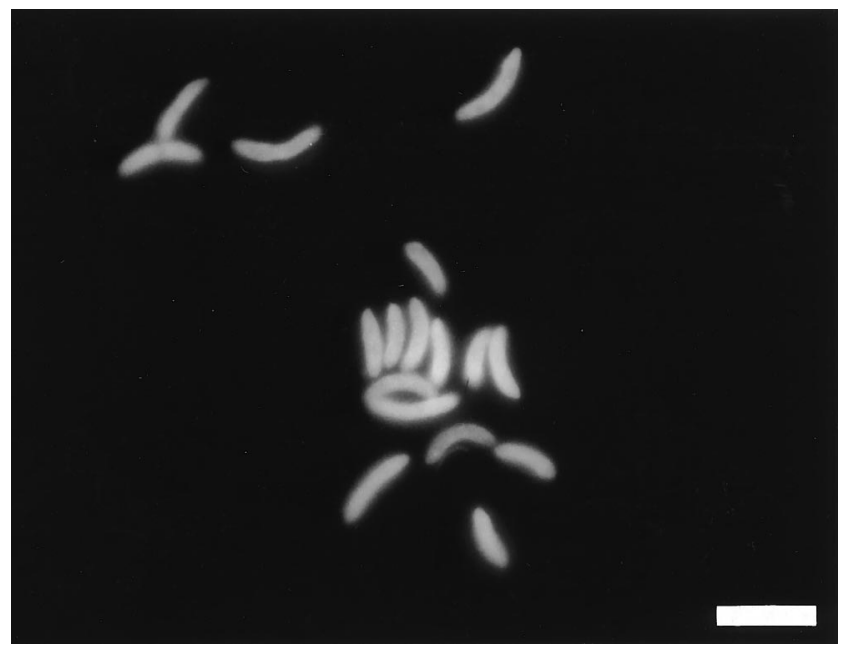

FIG. 3. Micrograph showing DAPI-stained microorganisms from Lago di Cadagno after sorting with gate 2 (Fig. 2). Bar, $10 \mu \mathrm{m}$.

contained almost exclusively individual cells and clusters of large cocci (diameter, approximately $3 \mu \mathrm{m}$ ) which, based on their morphology and autofluorescence, could provisionally be affiliated with the genus Amoebobacter (39). The large curved rods described above were obtained by sorting with gate 2 in nearly $100 \%$ purity, as confirmed by microscopy (Fig. 3). Molecular analysis of this fraction has been initiated.

Sorting of activated-sludge bacteria hybridized with fluorescein-labeled oligonucleotides. Activated-sludge samples were hybridized with two different fluorescein-labeled, rRNA-targeted oligonucleotide probes. Probe-positive cells were sorted directly onto microscopic slides to evaluate the purity of the sorted cells according to their staining and morphology (Table 2). Bacteria stained with the Acinetobacter spp.-specific probe ACA formed four distinct populations in the dot plot diagram (Fig. 4A and B). Microscopy revealed that cells sorted in gates 1,2 , and 3 (Fig. 4B) were mostly individual cocci, whereas gate 4 (Fig. 4B) was dominated by chains of coccobacilli that hybridized well with probe ACA (Fig. 5). Flow cytometric anal-

TABLE. 2. Purities and enrichment factors for different populations of probe-positive cells sorted from activated sludge after fluorescent in situ hybridization

\begin{tabular}{|c|c|c|c|c|c|}
\hline \multirow{2}{*}{ Probe } & \multirow{2}{*}{$\begin{array}{l}\text { Sort } \\
\text { gate }^{a}\end{array}$} & \multicolumn{2}{|c|}{$\begin{array}{l}\text { Probe-positive } \\
\text { cells/DAPI- } \\
\text { stained cells }\end{array}$} & \multirow{2}{*}{$\begin{array}{c}\text { Enrichment } \\
\text { factor }\end{array}$} & \multirow{2}{*}{ Morphology } \\
\hline & & $\begin{array}{l}\text { Before } \\
\text { sorting }^{b} \\
(\%)\end{array}$ & $\begin{array}{c}\text { After } \\
\text { sorting }^{c} \\
(\%)\end{array}$ & & \\
\hline $\mathrm{ACA}$ & 1 & 0.6 & 53 & 88 & Cocci, $1.5-2.5 \mu \mathrm{m}^{d}$ \\
\hline ACA & 2 & 0.4 & 66 & 165 & Cocci, 2.5-3.5 $\mu \mathrm{m}^{d}$ \\
\hline $\mathrm{ACA}$ & 3 & 0.3 & 84 & 280 & Cocci, $3.5-4.5 \mu \mathrm{m}^{d}$ \\
\hline ACA & 4 & 0.3 & 35 & 117 & $\begin{array}{l}\text { Coccobacilli in chains, } \\
1-2 \times 0.8 \mu \mathrm{m}\end{array}$ \\
\hline LDI & 5 & 12 & 82 & 7 & $\begin{array}{l}\text { Small rods, often in pairs, } \\
1.5-2.5 \times 0.8 \mu \mathrm{m}\end{array}$ \\
\hline LDI & 6 & 13 & 69 & 5 & $\begin{array}{l}\text { Large rods, often in pairs, } \\
2.5-4 \times 1 \mu \mathrm{m}\end{array}$ \\
\hline
\end{tabular}

\footnotetext{
${ }^{a}$ Sort gate numbering as in Fig. $4 \mathrm{~B}$ and D.

${ }^{b}$ Calculated from flow cytometric analysis.

${ }^{c}$ Calculated from microscopic counts of cells sorted directly onto slides.

${ }^{d}$ Range of cell diameters.
} 


\section{analysis mode}
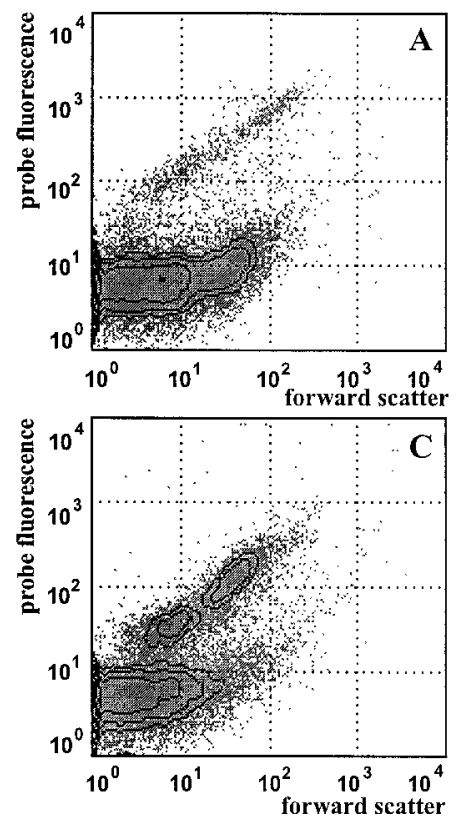

sorting gates
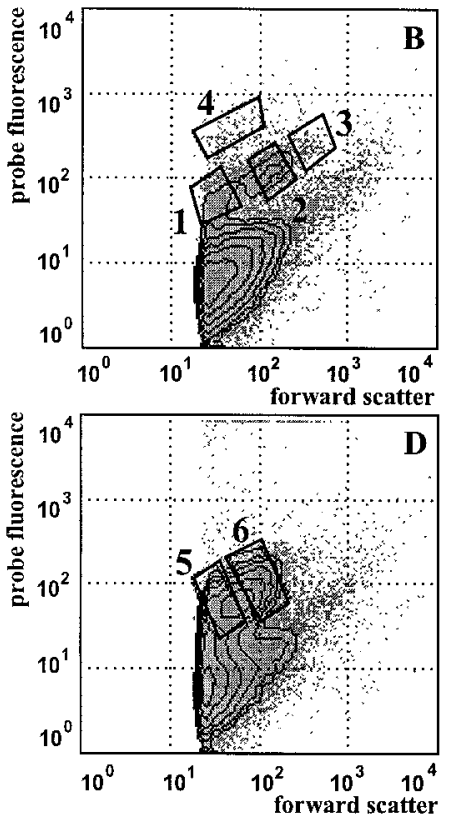

ACA

LDI

FIG. 4. Flow cytometric analysis and sorting of activated-sludge samples hybridized with specific probes for Acinetobacter spp. (ACA) and Leptothrix spp. (LDI). $x$ axis, forward light scatter; $y$ axis, fluorescence per cell. (A and C) Results obtained in the analysis mode. Note the discrimination of distinct populations. (B and D) Sorting gates. Because of increased background noise the threshold value for forward light scatter had to be set to a higher level during sorting, resulting in the topographical differences between panels $\mathrm{A}$ and $\mathrm{B}$ and between panels $\mathrm{C}$ and $\mathrm{D}$.

ysis of activated sludge hybridized with the Leptothrix spp.specific probe LDI (Fig. 4C) discriminated two populations which corresponded to small and large rods. The two populations were sorted in gates 5 and 6 (Fig. 4D). The high morphological heterogeneity of LDI-positive cells in the original activated-sludge sample is demonstrated in Fig. 6A and B. In contrast, the large rods sorted in gate 6 were much more homogeneous (Fig. 6C and D) with diameters around $1 \mu \mathrm{m}$ and a length of 2.5 to $4 \mu \mathrm{m}$. However, comparison of the fluorescent signals obtained from an identical microscopic field with a DAPI-specific filter set (Fig. 6C) and a fluoresceinspecific filter set (Fig. 6D) clearly demonstrated that nontarget cells exhibiting DAPI but no fluorescein fluorescence were still present in the sorted cell preparation. The frequency of LDIpositive cells could be increased by a factor of 5 to 6 from about 12 to $82 \%$ (gate 5) and to $69 \%$ (gate 6). For ACA the enrichment factor was about 90 - to 280 -fold, from less than $1 \%$ to 35 to $84 \%$ for all four gates (Table 2). Purity after sorting from gate 4 is rather low because the chains of target cells contained an epigrowth of small nontarget cells (Fig. 5). Furthermore, this gate also encompassed small flocs that contained nontarget cells in addition to ACA-positive cells.

Flow cytometric reanalysis. The enrichment effect of sorting was also demonstrated by flow cytometric reanalysis. For this experiment activated sludge was hybridized again with the Acinetobacter spp.-specific probe ACA. As in Fig. 4A and B
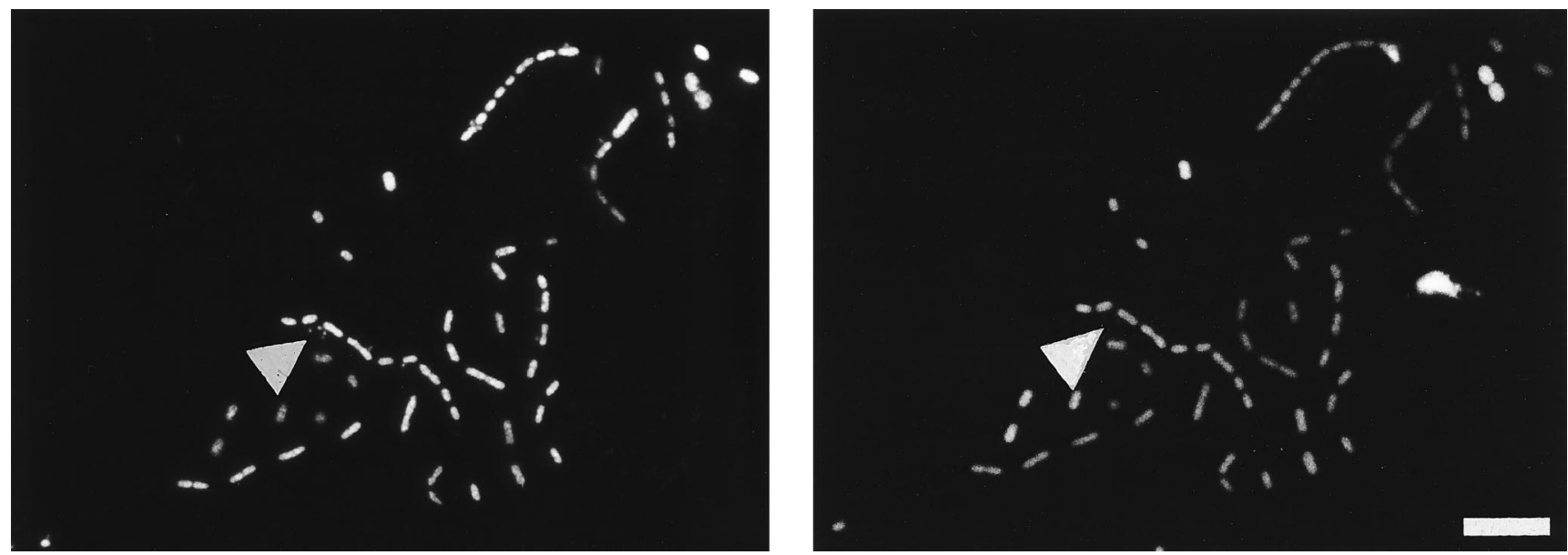

FIG. 5. Cells sorted from gate 4 (Fig. 4B) after hybridization of activated sludge with Acinetobacter spp.-specific probe ACA. DAPI fluorescence (left) and probe-conferred fluorescence (right) are shown. Bar, $10 \mu \mathrm{m}$. Arrowheads highlight bacterial epigrowth stained only with DAPI and not hybridizing with probe ACA. 


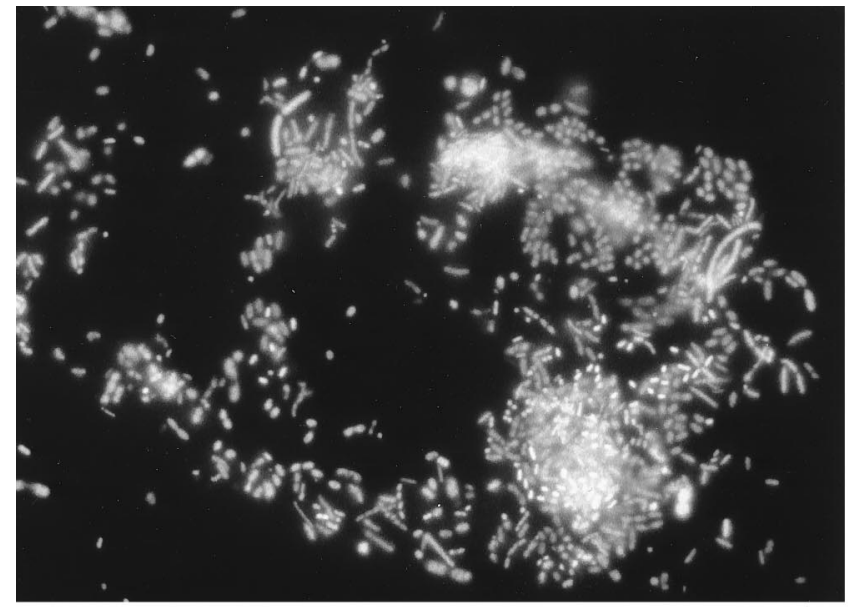

A

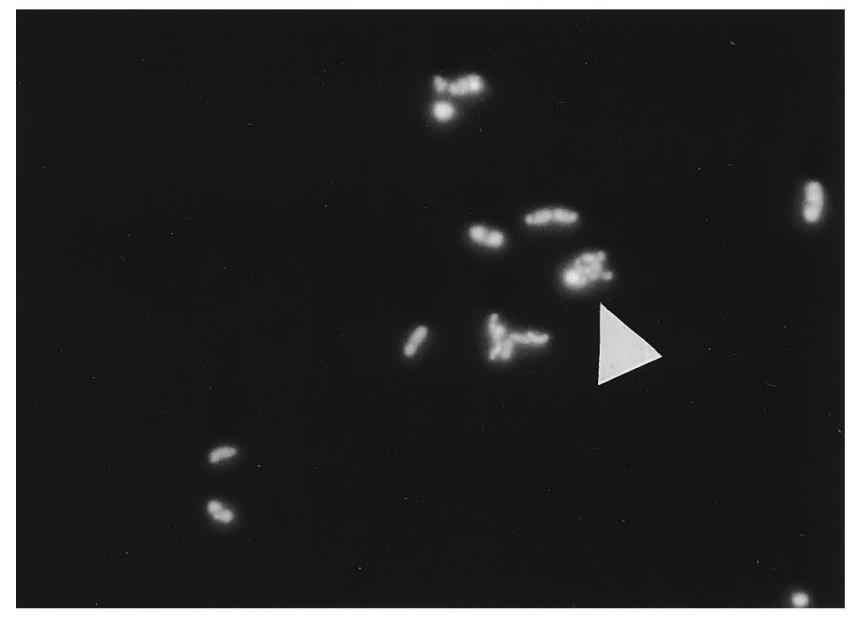

$\mathcal{C}$

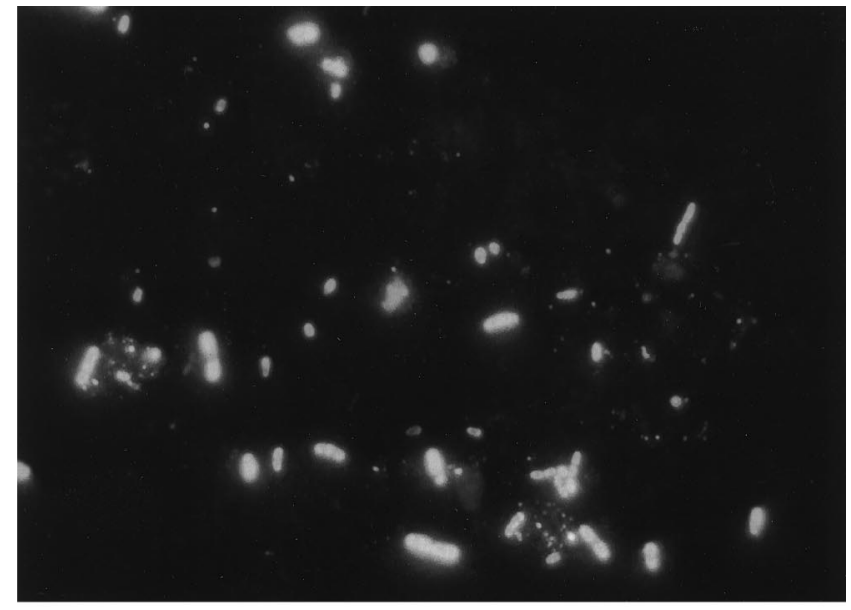

B

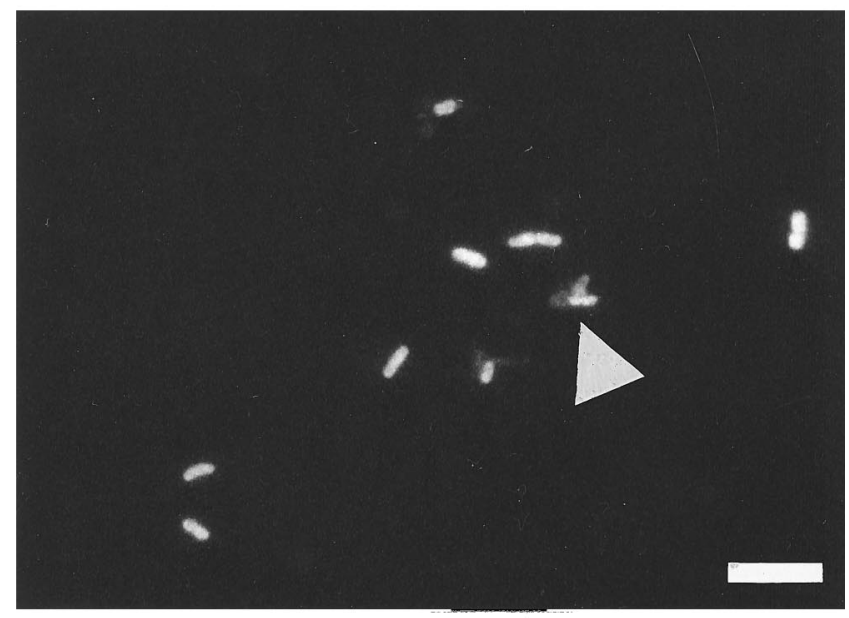

D

FIG. 6. Sorting of cells from activated sludge hybridizing with Leptothrix spp.-specific probe LDI sludge. The heterogeneity of LDI-positive cells in activated sludge before sorting is shown in panels A and B. Panels C and D show the large LDI-positive rods sorted from gate 6 (Fig. 4D). (A and C) Micrographs done with a DAPI-specific filter set. All cells present in the respective cell preparation are shown. (B and D) Micrographs done with a fluorescein-specific filter set. Only cells hybridized with probe LDI are visualized. Bar, $10 \mu \mathrm{m}$. Arrowheads in panels C and D highlight bacterial epigrowth stained only with DAPI and not hybridizing with probe LDI.

several discrete populations can be seen. The sorting gates $\mathrm{B}$ and $\mathrm{A}$ in Fig. 7 (left) are similar to gate 1 and the combination of gates 2 and 3 shown in Fig. 4B. The cell fractions sorted in gates A (Fig. 7, middle) and B (Fig. 7, right) are mapped by flow cytometric reanalysis in those region that had been defined by the respective sort window. The flow cytometric reanalysis also demonstrates high purity. The dots in the lower left corners (first decade of the $x$ and $y$ axes) originate mainly from the noncellular background, i.e., particles and instrument noise.

Repeated sorting. The effect of a second sorting step was evaluated for ACA-positive cells sorted from gate 2 (Fig. 4B). The purity could be clearly enhanced. From initial purities of 76,54 , and $66 \%$, a second sorting step with the same gate 2 enhanced the purities to 91,76 , and $88 \%$, respectively. After a second sorting step only nontarget cells could be detected microscopically that were physically attached to probe-positive cells (data not shown).
PCR amplification of $16 \mathrm{~S}$ rDNA from fixed cells. Bacteria from different phylogenetic groups were tested for the feasibility of amplification of $16 \mathrm{~S}$ rDNA from ethanol- and paraformaldehyde-fixed cells. Amplification with standard PCR primers yielded specific amplification products from 10 paraformaldehyde-fixed gram-negative strains (B. diminuta, $P$. denitrificans, L. cholodnii, L. discophora, A. baumannii, A. hydrophila, E. cloacae, E. coli, C. johnsonii, H. hydrossis) and 5 ethanol-fixed gram-positive strains (M. imperiali, $R$. rhodochrous, N. calcarea, M. kristinae, B. subtilis). Despite applying a freeze-thaw procedure prior to amplification no PCR product could be obtained from the sheathed beta-subclass proteobacterium $S$. natans or the gamma-subclass proteobacterium $T$. nivea. The minimum numbers of cells for reproducibly obtaining detectable amplification products were approximately 1,000 cells for B. subtilis and 500 cells for E. coli. There was no significant difference between logarithmic- and stationarygrowth-phase cells. For cells sorted after hybridization with 


\section{before sorting}

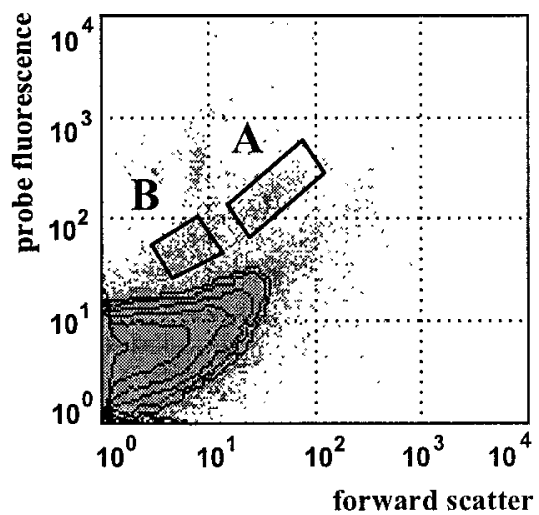

\section{after sorting}

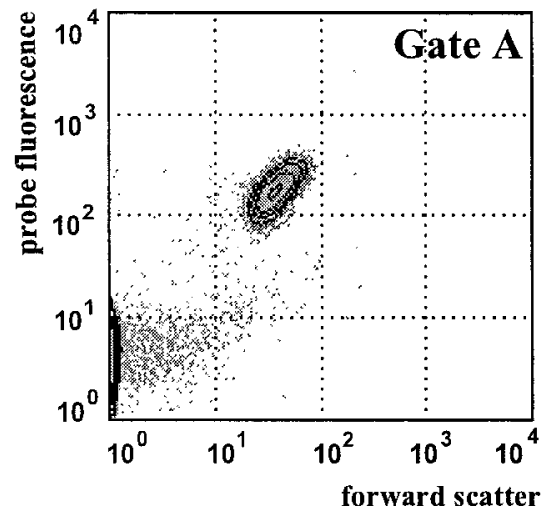

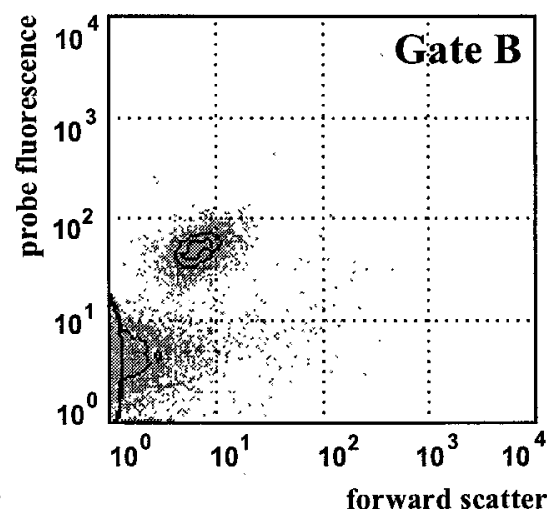

FIG. 7. Reanalysis of sorted cell fractions. Activated sludge was hybridized with Acinetobacter spp.-specific probe ACA, and then two populations were gated for sorting (left). Sorted cells were reanalyzed in the flow cytometer. Middle panel shows cells reanalyzed from gate A; right panel shows cells reanalyzed from gate B.

fluorescent oligonucleotide probes of different specificities usually 10,000 cells were sufficient to yield detectable PCR products.

Cloning of a PCR product from LDI-sorted cells. To investigate the frequency of undesired sequences, we amplified the 16S rDNA of LDI-positive cells obtained by sorting with gate 6 (Fig. 4). The PCR product was cloned in a T-Vector system. Plasmid DNA containing the $16 \mathrm{~S}$ rDNA sequences as insert was isolated from 84 clones, dotted on a nylon membrane together with $16 \mathrm{~S}$ rDNA from five reference strains, and screened with the HRP-labeled probes EUB, LDI, and ACA. The specificity of probe LDI at the hybridization conditions used was shown by dot blot hybridization signals of DNA from the target organisms $L$. discophora and A. metamorphum but not with DNA from the nontarget organisms $S$. yanoikuyae, $C$. johnsonii, and $A$. baumanii. Only $A$. baumanii gave a positive reaction with probe ACA, which served as a negative control for all other species. All plasmid preparations contained similar amounts of rDNA as assessed by probe EUB. Seventy-one of the 84 clones $(85 \%)$ included inserts which hybridized with probe LDI. These data demonstrate the strong enrichment of the desired cells also on the level of amplified and cloned rDNA.

Sequence data. The $16 \mathrm{~S}$ rDNA sequence of one of the 71 LDI-positive clones was determined in almost full length (accession no. AJ001325; EMBL Nucleotide Sequence Database). The sequences of six additional clones were partially determined and shown to be over $99 \%$ similar to the first sequence (data not shown). The target sequence of probe LDI used for sorting could be found in all clones sequenced. Comparison of these newly retrieved sequences with $>6,00016 \mathrm{~S}$ rRNA sequences available in the TUM database (16) revealed no complete identity with already sequenced organisms. Distance matrix analysis showed high similarities $(>98 \%)$ with $16 \mathrm{~S}$ rDNA sequences of clones T25, T19, and T41 from cluster I (31) derived from activated sludge, which form a new, distinct group within the $\beta 1$-subgroup of the class Proteobacteria.

\section{DISCUSSION}

The advantages of flow sorting. Both the classical cultivation-based methods and the modern molecular methods for studying microbial diversity may be biased by selective recovery (4). This positive or negative discrimination of certain taxa introduced by cultivation or molecular techniques is often un- intended and undefined. In contrast, diversity research on cell fractions obtained by flow sorting is based on an intended and defined selection for any cellular property that can be measured or assessed by flow cytometry.

The basis for the sorting decision. In this study, sorting was attempted for conspicuous cells that were either not very abundant or that could otherwise not be analyzed by molecular techniques. These cells of interest differed from the other cells present in the investigated sample in either their cell size, their internal structure, or their staining with DAPI or the phylogenetic probes. In general, the following traits can be used for flow cytometric discrimination: (i) cell size as recorded by forward light scattering, (ii) internal structures as seen in the $90^{\circ}$-angle light scattering, and (iii) intensity of fluorescence in a certain spectral region. A single parameter is usually not sufficient to delineate a population in a heterogeneous microbial community, but FCM offers the advantage that several parameters can be measured simultaneously. Therefore, bivariate dot plots of the different parameters were analyzed for maximum discrimination of the cells of interest from the background. In the examples presented here, all sorting decisions were based on the combination of forward scatter (cell size) with a second parameter.

In the case of the magnetotactic bacteria the second parameter was the strong side-scatter signal caused by the high intracellular content of magnetosomes. Here, it was possible to base the sorting decision solely on internal structure and cell size as measured in the two scatter channels. For sorting of curved rods from Lago di Cadagno an unusually strong staining with DAPI was the basis for differentiation of cells of interest from bacteria with a similar forward scatter. By trial and error, drawing of sort gates around more or less distinct populations, and microscopic analysis of the respective sorted cells, the conspicuous bacteria could be obtained in high purity. Both cases are examples that relatively nonspecific parameters can be sufficient for the discrimination of the microorganisms of interest.

In contrast, sorting of cells from activated sludge was based on the combination of forward light scatter with the highly specific fluorescent signal conferred by an rRNA-targeted oligonucleotide probe. Based on $16 \mathrm{~S}$ and $23 \mathrm{~S}$ rRNA sequence data most microorganisms can be discriminated to species level (4). Of the three different types of samples investigated in this study, enrichments of magnetotactic bacteria, lake water, and 
activated sludge, the latter was the most complex one. Nevertheless, the assessment of cell size and rRNA type allowed sorting of homogeneous populations.

If necessary, sorting decisions could, of course, also be based on the correlation of three or more parameters. This opens up possibilities for sorting according to the binding of several rRNA-targeted oligonucleotide probes labeled with different fluorochromes along the lines of the multiple-probe approach $(1,4)$. Alternatively, one of the additional parameters used for sorting could also be the autofluorescence of photosynthesis pigments (29) or the binding of fluorescently labeled antibodies (47).

Enrichment factor and purity of sorted cells. The efficacy of sorting can be expressed either by the enrichment factor, as defined by the relative abundance after sorting divided by the relative abundance before sorting, or by the purity of the sorted cells. The M. bavaricum in the enrichment of magnetotactic bacteria ( $50 \%$ original abundance) and the large curved rods in the lake water $(<5 \%)$ could be sorted to almost $100 \%$ purity, yielding enrichment factors of 2 and greater than 20 , respectively. Sorting of probe-positive cells from activated sludge yielded even higher enrichment factors of up to 280, at least for those populations that were originally present only at low concentrations. Nevertheless, the sorted cells always contained unwanted cell types and were only enriched to 35 to $84 \%$ purity. There were two major reasons for this. Activated sludge contains cell clusters in which nontarget cells can be tightly adhered to cells of interest. Even though hybridization in the presence of detergents and shear forces during hydrodynamic focusing in the flow chamber result in detachment of cells from aggregates (46), a perfect single-cell suspension is never achieved. Especially when small nontarget cells are attached to large individual cells or to clusters of cells of interest they do not affect the light scatter sufficiently to be recognized and discriminated as heterogeneous aggregates during sorting (see Fig. 5 and 6). Similar epigrowth phenomena were absent in the other two samples sorted, the enrichment of magnetotactic bacteria and lake water, in which higher purities were achieved. Stable adherence of unwanted cells to target cells is likely the main reason for the purity differences in samples with similar original concentrations. The second factor which favors sorting of unwanted cells is an increase of background events compared to regular flow cytometric analysis, mainly in the light scatter channels and due to electronic noise from the sorting device and to additional reflections on the surface of the water jet during droplet generation. Therefore, the threshold for forward or side scatter has to be increased, and consequently, the flow cytometer becomes blind for small cells with signals lower than the threshold value. These cannot be detected and excluded by the sort software anymore, and they end up in the sorted cell preparation if they travel randomly, without being physically attached, in the vicinity of target cells.

Consequently, we attribute the fact that a second sort step clearly enhanced the purity of cells sorted from activated sludge (from 54 to $76 \%$ to 76 to $91 \%$ ) mainly to the lower probability of the target and nontarget cells being in close vicinity in the resorted sample, which had been considerably diluted by sheath water during the initial sorting. Also, additional detachment of epigrowth during the second passage through the flow cytometer might have been a factor. Dilution of the sample before the first sort step would also increase the purity of the sorted cell fraction, but the time required for obtaining sufficient cell numbers would rise as well. In particular, for populations of low abundance, enrichment of the wanted cells in a first sort cycle and purification in a second sort cycle would be the most reasonable approach. In principle, each additional sort step would further increase the purity of the sorted population, but this approach is limited by aggregates of target and nontarget cells that can neither be physically dispersed nor discriminated by FCM analysis.

Molecular analysis of sorted cells. With the flow cytometer used in this study a few minutes were sufficient to sort 1,000 to 10,000 cells. Even though this is a high number compared to what can be sorted in the same time by micromanipulators (30) or optical tweezers (13) this is still not sufficient for standard molecular techniques such as DNA or rRNA extraction. Therefore, subsequent analysis requires highly sensitive molecular methods. Successful PCR amplification of $16 \mathrm{~S}$ rDNA from whole bacterial cells has been described before (33). Likely, at least part of the cells are lysed at the high temperatures of thermal cycling and the released DNA becomes available for amplification. Since the sorted cells will usually be further stabilized by fixatives such as the cross-linking aldehydes or the denaturing alcohols it was necessary to adjust and evaluate PCR-based methods.

The initial qualitative study of the influence of cell fixation on various bacteria yielded rDNA amplificates in 15 of 17 cases. After freeze-thawing even gram-positive strains could be amplified. Interestingly, from two gram-negative strains no PCR product could be obtained. Sulfur granules and sheath components such as polysaccharides might have inhibited the $T a q$ polymerase in the cases of $T$. nivea and $S$. natans, respectively. Since we had no particular interest in these organisms we did not optimize the PCR amplification. However, given some effort, it should be possible to find a suitable combination of cell permeabilization and the removal of interfering cell components that would allow rDNA amplification of any batch of several thousand sorted cells. Quantitative studies on fixed cells of $E$. coli and $B$. subtilis showed that a minimum number of 500 and 1,000 cells, respectively, have to be present to reproducibly obtain detectable rDNA amplificates. These relatively high minimum cell numbers indicate that with the techniques applied in this study only a minor fraction of the $16 \mathrm{~S}$ rDNA genes is available for amplification by the Taq polymerase. Probably most rDNA genes remain inside fixed cells, separated from the enzyme by the dense network of the fixed cell wall. In addition, negative effects of formaldehyde fixation on the efficacy and fidelity of PCR amplification of DNA have been described elsewhere (9).

Limitations. Flow cytometers available today have a lower sensitivity than epifluorescence microscopes. Therefore, the smaller bacterial cells cannot always be reasonably analyzed or sorted. As outlined above present flow cytometers operating in the sort mode have a high noise level in the light scatter channels. So especially if forward- or side-angle light scattering is to be used as a discriminating parameter, which is often advisable, sorting is restricted to fairly large $(>1 \mu \mathrm{m})$ and strongly fluorescent bacterial cells. As a matter of fact most environmental bacteria are smaller than $1 \mu \mathrm{m}$. However, if new highly sensitive flow cytometers for the detection of even small DNA fragments also become available for cell sorting, the threshold of detection may be considerably lowered (12). Furthermore, even with highly sensitive epifluorescence microscopes, only about $50 \%$ of total microorganisms (as defined by DAPI staining) in meso- and oligotrophic lakes can be detected by fluorescent in situ hybridization with rRNA-targeted oligonucleotide probes (10). This might be due to either low cellular ribosome contents or probe impermeability of cell walls (4). In the future, these limitations might be overcome by flow cytometers with a higher sensitivity for light scattering and fluorescence or by new labeling techniques that yield stronger 
signals, e.g., by in situ PCR $(11,21)$ or signal amplification techniques (27).

The initial abundance of cells of interest in the original sample may be rather low provided that they can be clearly distinguished from other cells by their flow cytometric characteristics. In this study, cells with an abundance of $0.3 \%$ could be easily detected and highly enriched by flow sorting. Recently, we even achieved retrieval of a large, strongly fluorescent spirillum with an original abundance of approximately $0.01 \%$ (32). At the current maximum sorting speed of $5 \times 10^{3}$ events per second, cells at even lower abundances are hard to obtain in sufficient number. This is not only due to the long sorting times but also to the fact that it becomes very difficult to define a proper sorting gate. Both problems may be solved by repeated sort cycles (see above). By an initial step with a wide sort gate the relative abundance of the cells of interest should be raised to a level that allows definition of a narrow sort gate for the second run.

Future perspectives. Here, we evaluated the potential of flow cytometric cell sorting to assist analysis of the diversity and structure of microbial communities based on the rRNA approach (4). However, sorted cells could be subjected to various other methods for further characterization, as long as these methods can be applied to relatively low numbers of cells. PCR-based studies could, for instance, be used to investigate the presence of functional genes or, by (semi-) quantitative reverse transcription-PCR analysis of mRNAs, their expression. Electron microscopic studies have the potential to study not only the ultrastructure but also the elemental composition of single cells. Radiolabeled substrates would allow studies of basic activities like DNA replication, transcription, translation, or primary production in environmental samples. In the future such techniques could, if based on sorted cells, be related to defined populations and thereby be liberated from the drawbacks of bulk measurements.

\section{ACKNOWLEDGMENTS}

We thank Sibylle Schadhauser for excellent technical assistance and M. Tonolla (Lugano, Switzerland) and R. Bachofer (Zurich, Switzerland) for hospitality and sampling assistance at Lago di Cadagno.

This work was supported by a grant of the Bundesministerium für Bildung und Forschung (BMBF 21P1624).

\section{REFERENCES}

1. Amann, R., J. Snaidr, M. Wagner, W. Ludwig, and K.-H. Schleifer. 1996. In situ visualization of high genetic diversity in a natural microbial community. J. Bacteriol. 178:3496-3500.

2. Amann, R. I., B. J. Binder, R. J. Olson, S. W. Chisholm, R. Devereux, and D. A. Stahl. 1990. Combination of 16S rRNA-targeted oligonucleotide probes with flow cytometry for analyzing mixed microbial populations. Appl. Environ. Microbiol. 56:1919-1925.

3. Amann, R. I., L. Krumholz, and D. A. Stahl. 1990. Fluorescent-oligonucleotide probing of whole cells for determinative, phylogenetic, and environmental studies in microbiology. J. Bacteriol. 172:762-770.

4. Amann, R. I., W. Ludwig, and K.-H. Schleifer. 1995. Phylogenetic identification and in situ detection of individual microbial cells without cultivation. Microbiol. Rev. 59:143-169.

5. Brosius, J., T. J. Dull, D. D. Sleeter, and H. F. Noller. 1981. Gene organization and primary structure of a ribosomal RNA operon from Escherichia coli. J. Mol. Biol. 148:107-127.

6. Button, D. K., B. R. Robertson, and F. Jüttner. 1996. Microflora of a subalpine lake: bacterial populations, size and DNA distributions, and their dependence on phosphate. FEMS Microbiol. Ecol. 21:87-101.

7. Chen, E. Y., and P. H. Seeburg. 1985. Supercoil sequencing: a fast and simple method for sequencing plasmid DNA. DNA 4:165-170.

8. Davey, H. M., and D. B. Kell. 1996. Flow cytometry and cell sorting of heterogeneous microbial populations: the importance of single-cell analysis. Microbiol. Rev. 60:641-696.

9. DeGiorgi, C., M. F. Sialer, and F. Lamberti. 1994. Formalin-induced infidelity in PCR-amplified DNA fragments. Mol. Cell. Probes 8:459-462.

10. Glöckner, F. O., R. Amann, A. Alfreider, J. Pernthaler, R. Psenner, K.
Trebesius, and K.-H. Schleifer. 1996. An optimized in situ hybridization protocol for planktonic bacteria. Syst. Appl. Microbiol. 19:403-406.

11. Hodson, R. E., W. E. Dustman, R. P. Garg, and M. A. Moran. 1995. In situ PCR for visualization of microscale distribution of specific genes and gene products in prokaryotic communities. Appl. Environ. Microbiol. 61:40744082.

12. Huang, Z., J. T. Petty, B. O'Quinn, J. L. Longmire, N. C. Brown, J. H. Jett, and R. A. Keller. 1996. Large DNA fragment sizing by flow cytometry: application to the characterization of P1 artifical chromosome (PAC) clones. Nucleic Acids Res. 24:4202-4209.

13. Huber, R., S. Burggraf, T. Mayer, S. M. Barns, P. Rossnagel, and K. O. Stetter. 1995. Isolation of a hyperthermophilic archaeum predicted by in situ RNA analysis. Nature 376:57-58.

14. Lee, D.-H., Y.-G. Zo, and S.-J. Kim. 1996. Nonradioactive method to study genetic profiles of natural bacterial communities by PCR-single-strand-conformation polymorphism. Appl. Environ. Microbiol. 62:3112-3120.

15. Lim, E. L., L. A. Amaral, D. A. Caron, and E. F. DeLong. 1993. Application of rRNA-based probes for observing marine nanoplanktonic protists. Appl. Environ. Microbiol. 59:1647-1655.

16. Ludwig, W. 1995. Sequence databases, 3.3.5., p. 1-22. In A. D. L. Akkerman, J. D. van Elsas, and F. J. de Bruijn (ed.), Molecular microbial ecology manual. Kluwer Academic Publishers, Dordrecht, The Netherlands.

17. Manz, W., R. Amann, W. Ludwig, M. Wagner, and K.-H. Schleifer. 1992. Phylogenetic oligodeoxynucleotide probes for the major subclasses of proteobacteria: problems and solutions. Syst. Appl. Microbiol. 15:593-600.

18. Muyzer, G., E. C. de Waal, and A. G. Uitterlinden. 1993. Profiling of complex microbial populations by denaturing gradient electrophoresis analysis of polymerase chain reaction-amplified genes encoding for 16S rRNA. Appl. Environ. Microbiol. 59:695-700.

19. Olsen, G. J., D. J. Lane, S. J. Giovannoni, N. R. Pace, and D. A. Stahl. 1986. Microbial ecology and evolution: a ribosomal rRNA approach. Annu. Rev. Microbiol. 40:337-365.

20. Picard, C., C. Ponsonnet, E. Paget, X. Nesme, and P. Simonet. 1992. Detection and enumeration of bacteria in soil by direct DNA extraction and polymerase chain reaction. Appl. Environ. Microbiol. 58:2717-2722.

21. Porter, J., R. Pickup, and C. Edwards. 1995. Flow cytometric detection of specific genes in genetically modified bacteria using in situ polymerase chain reaction. FEMS Microbiol. Lett. 134:51-56.

22. Porter, J., D. Deere, R. Pickup, and C. Edwards. 1996. Fluorescent probes and flow cytometry: new insights into environmental bacteriology. Cytometry 23:91-96.

23. Rainey, F. A., N. Ward, L. I. Sly, and E. Stackebrandt. 1994. Dependence of the taxon composition of clone libraries for PCR amplified, naturally occurring $16 \mathrm{~S}$ rDNA on the primer pair and the cloning system used. Experientia 50:796-797.

24. Reysenbach, A., L. J. Giver, G. S. Wickham, and N. R. Pace. 1992. Differential amplification of rRNA genes by polymerase chain reaction. Appl. Environ. Microbiol. 58:3417-3418.

25. Robertson, B. R., and D. K. Button. 1989. Characterizing aquatic bacteria according to population, cell size, and apparent DNA content by flow cytometry. Cytometry 10:70-76.

26. Sahar, E., R. Lamed, and I. Ofek. 1983. Rapid identification of Streptococcus pyogenes by flow cytometry. Eur. J. Clin. Microbiol. 2:192-195.

27. Schönhuber, W., B. Fuchs, S. Juretschko, and R. Amann. 1997. Improved sensitivity of whole-cell hybridization by the combination of horseradish peroxidase-labeled oligonucleotides and tyramide signal amplification. Appl. Environ. Microbiol. 63:3268-3273.

28. Shapiro, H. M. 1995. Practical flow cytometry, 3rd ed. Alan R. Liss, Inc., New York, N.Y.

29. Simon, N., N. LeBot, D. Marie, F. Partensky, and D. Vaulot. 1995. Fluorescent in situ hybridization with rRNA-targeted oligonucleotide probes to identify small phytoplankton by flow cytometry. Appl. Environ. Microbiol. 61:2506-2513.

30. Skerman, V. B. D. 1968. A new type of micromanipulator and microforge. J. Gen. Microbiol. 54:287-297.

31. Snaidr, J., R. Amann, I. Huber, W. Ludwig, and K.-H. Schleifer. 1997. Phylogenetic analysis and in situ identification of bacteria in activated sludge. Appl. Environ. Microbiol. 63:2884-2896.

32. Snaidr, J., B. Fuchs, G. Wallner, and R. Amann. Unpublished data.

33. Spring, S., R. Amann, W. Ludwig, K.-H. Schleifer, and N. Petersen. 1992. Phylogenetic diversity and identification of nonculturable magnetotactic bacteria. Syst. Appl. Microbiol. 15:116-122.

34. Spring, S., R. Amann, W. Ludwig, K.-H. Schleifer, H. van Gemerden, and N. Petersen. 1993. Dominating role of an unusual magnetotactic bacterium in the microaerophilic zone of a freshwater sediment. Appl. Environ. Microbiol. 59:2397-2403.

35. Spring, S., R. Amann, W. Ludwig, K.-H. Schleifer, D. Schüler, K. Poralla, and N. Petersen. 1994. Phylogenetic analysis of uncultured magnetotactic bacteria from the alpha-subclass of proteobacteria. Syst. Appl. Microbiol. 17:501-508.

36. Steen, H. B. 1990. Light scattering measurement in an arc lamp-based flow cytometer. Cytometry 11:223-230. 
37. Steen, H. B. 1992. Noise, sensitivity, and resolution of flow cytometers. Cytometry 13:822-830.

38. Strunk, O., O. Gross, B. Reichel, M. May, S. Hermann, N. Stuckman, B. Nonhoff, M. Lenke, A. Ginhart, A. Vilbig, T. Ludwig, A. Bode, K.-H. Schleifer, and W. Ludwig. ARB: a software environment for sequence data. http:// www.mikro.biologie.tu-muenchen.de. Department of Microbiology, Technische Universität München, Munich, Germany.

39. Tonolla, M. Personal communication.

40. Urdea, M. S., B. D. Warner, J. A. Running, M. Stempien, J. Clyne, and T. Horn. 1988. A comparison of non-radioisotopic hybridization assay methods using fluorescent, chemiluminescent and enzyme labeled synthetic oligonucleotide probes. Nucleic Acids Res. 16:4937-4956.

41. Völsch, A., W. F. Nader, H. K. Geiss, G. Nebe, and C. Birr. 1990. Detection and analysis of two serotypes of ammonia-oxidizing bacteria in sewage plants by flow cytometry. Appl. Environ. Microbiol. 56:2430-2435.

42. Wagner, M., R. Amann, P. Kämpfer, B. Aßmus, A. Hartmann, P. Hutzler, N. Springer, and K.-H. Schleifer. 1994. Identification and in situ detection of gram-negative filamentous bacteria in activated sludge. Syst. Appl. Microbiol. 17:405-417.
43. Wagner, M., R. Amann, H. Lemmer, and K. H. Schleifer. 1993. Probing activated sludge with oligonucleotides specific for proteobacteria: inadequacy of culture-dependent methods for describing microbial community structure. Appl. Environ. Microbiol. 59:1520-1525.

44. Wagner, M., R. Erhart, W. Manz, R. Amann, H. Lemmer, D. Wedi, and K. H. Schleifer. 1994. Development of an rRNA-targeted oligonucleotide probe specific for the genus Acinetobacter and its application for in situ monitoring in activated sludge. Appl. Environ. Microbiol. 60:792-800.

45. Wallner, G., R. Amann, and W. Beisker. 1993. Optimizing fluorescent in situ hybridization with rRNA-targeted oligonucleotide probes for flow cytometric identification of microorganisms. Cytometry 14:136-143.

46. Wallner, G., R. Erhart, and R. Amann. 1995. Flow cytometric analysis of activated sludge with rRNA-targeted probes. Appl. Environ. Microbiol. 61: 1859-1866.

47. Wallner, G., I. Steinmetz, D. Bitter-Suermann, and R. Amann. 1996. Combination of rRNA-targeted hybridization probes and immuno-probes for the identification of bacteria by flow cytometry. Syst. Appl. Microbiol. 19:569576 